\title{
$\mathrm{HbA}_{1 \mathrm{c}}$ levels in schoolchildren with type 1 diabetes are seasonally variable and dependent on weather conditions
}

\author{
B. Mianowska • W. Fendler • A. Szadkowska • \\ A. Baranowska • E. Grzelak-Agaciak • J. Sadon • \\ H. Keenan - W. Mlynarski
}

Received: 2 September 2010 / Accepted: 18 November 2010 /Published online: 25 December 2010

(C) The Author(s) 2010. This article is published with open access at Springerlink.com

\begin{abstract}
Aims/hypothesis We evaluated seasonal $\mathrm{HbA}_{1 \mathrm{c}}$ changes in children with type 1 diabetes and its relation with measures of weather conditions.

Methods $\mathrm{HbA}_{1 \mathrm{c}}$ changes over more than 3 years were evaluated in type 1 diabetic patients who were younger than 18 years and had diabetes duration of more than 12 months, and correlated with measures of weather conditions (ambient temperature, hours of sunshine and solar irradiance). After comparison of autocorrelation patterns, patterns of metabolic control and meteorological data were evaluated using Spearman rank correlation.

Results A total of $3,935 \mathrm{HbA}_{1 \mathrm{c}}$ measurements in 589 school ( $\geq 7$ years) and 88 preschool $(<7$ years) children were analysed. Mean $( \pm \mathrm{SD}) \mathrm{HbA}_{1 \mathrm{c}}$ level for the whole study period was $7.65 \pm 1.12 \%$. The lowest $\mathrm{HbA}_{1 \mathrm{c}}$ levels
\end{abstract}

B. Mianowska and W. Fendler contributed equally to this study.

Electronic supplementary material The online version of this article (doi:10.1007/s00125-010-2013-4) contains supplementary material, which is available to authorised users.

B. Mianowska $\cdot$ W. Fendler $\cdot$ A. Szadkowska $\cdot$ A. Baranowska

W. Mlynarski $(\square)$

Department of Pediatrics, Oncology, Hematology and

Diabetology, Medical University of Lodz,

36/50 Sporna St,

91-738 Lodz, Poland

e-mail: Wojciech.Mlynarski@umed.lodz.p1

E. Grzelak-Agaciak · J. Sadon

Institute of Meteorology and Water Management,

Warsaw, Poland

\section{H. Keenan}

Department of Medicine/Harvard Medical School, Clinical Research Joslin Diabetes Center,

Boston, MA, USA were observed in late summer and the highest in winter months, with differences consistently exceeding $0.44 \%$. Autocorrelation analysis of $\mathrm{HbA}_{1 \mathrm{c}}$ levels in schoolchildren showed a sine-wave pattern with a cycle length of roughly 12 months, which mirrored changes in ambient temperature. Strong negative correlations of $\mathrm{HbA}_{1 \mathrm{c}}$ with ambient temperature $(R=-0.56 ; p=0.0002)$, hours of sunshine $(R=-0.52$; $p=0.0007)$ and solar irradiance $(R=-0.52 ; p=0.0006)$ were present in schoolchildren, but not in preschoolers $(p \geq 0.29$ for each correlation).

Conclusions/interpretation Seasonal changes of $\mathrm{HbA}_{1 \mathrm{c}}$ levels in schoolchildren with type 1 diabetes are a significant phenomenon and should be considered in patient education and diabetes management. They may potentially affect the results of clinical trials using $\mathrm{HbA}_{1 \mathrm{c}}$ levels as their primary outcome, as well as $\mathrm{HbA}_{1 \mathrm{c}}$-based diagnosis of diabetes.

Keywords Adolescents $\cdot$ Children $\cdot \mathrm{HbA}_{1 \mathrm{c}} \cdot$ Seasonal variation - Type 1 diabetes mellitus

\section{Abbreviation \\ NGSP National Glycohemoglobin Standardization Program}

\section{Introduction}

Glycated haemoglobin $\mathrm{A}_{1 \mathrm{c}}\left(\mathrm{HbA}_{1 \mathrm{c}}\right)$, which is formed through the non-enzymatic glycation of haemoglobin, is used as a cumulative estimate of mean blood glucose levels from the preceding 5-12 weeks in healthy people and in patients with diabetes [1]. It is a measure of glycaemic control commonly used as a predictor of diabetic micro- 
vascular complications in people with type 1 and type 2 diabetes [2]. As $\mathrm{HbA}_{1 \mathrm{c}}$ measurement and patient selfmonitoring of blood glucose are the two primary techniques used to assess the effectiveness of diabetes management [3], it is crucial to identify any factors that can bias these values. The recent changes in the ADA criteria for the diagnosis of diabetes [3] contribute to the importance of recognising any variation pertaining to $\mathrm{HbA}_{1 \mathrm{c}}$ levels, especially in those aged 7 years and older, as this is a key age interval for the diagnosis of type 1 diabetes mellitus in paediatric population. Seasonal changes of $\mathrm{HbA}_{1 \mathrm{c}}$ levels have been described in several studies assessing populations of adult patients with type 1 and type 2 diabetes [4-7]. Such fluctuations were also observed in children with type 1 diabetes [8-11]. However, most of the studies including paediatric age-groups had short observation periods or included relatively small groups of patients $[8,10]$, or were not primarily concerned with analysis of seasonal $\mathrm{HbA}_{1 \mathrm{c}}$ fluctuations; these reported relatively small differences in $\mathrm{HbA}_{1 \mathrm{c}}$ between the lowest and peak months $[9,11]$. Factors related to potential seasonal variations in $\mathrm{HbA}_{1 \mathrm{c}}$ levels in children have not been previously studied. In a recent study, including adult diabetes patients, Higgins et al. investigated the similarity of mean $\mathrm{HbA}_{1 \mathrm{c}}$ levels with temperature changes in locations spread across the globe, and showed that the amplitude of both variables is strongly correlated [12].

The aim of our study was to evaluate seasonal $\mathrm{HbA}_{1 \mathrm{c}}$ changes over more than 3 years (from August 2006 to October 2009) in a paediatric population of patients with type 1 diabetes. We also evaluated the relation of such changes with objective measures of weather conditions, which may reflect sun exposure and trends in physical activity.

\section{Methods}

Study population and laboratory data The study was performed in Lodz, an administrative district in central Poland with approximately 2.6 million inhabitants. Data were collected from a central, certified laboratory database, which performs $\mathrm{HbA}_{1 \mathrm{c}}$ testing for more than $90 \%$ of paediatric patients with diabetes in the region. Inclusion criteria were: (1) type 1 diabetes diagnosed on basis of clinical symptoms and laboratory results at onset; and (2) age below 18 years. Data from the laboratory database were cross-referenced by two independent researchers (A. Baranowska, W. Fendler) with the clinical database of patients with type 1 diabetes to verify patient status. Over the study period, August 2006 to October 2009, the laboratory method for assessment of $\mathrm{HbA}_{1 \mathrm{c}}$ was consistent. $\mathrm{HbA}_{1 \mathrm{c}}$ assays were performed by ion-exchange HPLC (Variant Hemoglobin A1c Program; Bio-Rad Laboratories, Hercules,
CA, USA). The method used has been certified by the National Glycohemoglobin Standardization Program (NGSP) (http://www.ngsp.org/docs/methods.pdf; last accessed 25 November 2010). Reference values for healthy people estimated by the local laboratory were from 4.3 to $5.7 \%$. The within-run $\mathrm{CV}$ determined by the manufacturer was $1.05 \%$ for people without diabetes and $0.94 \%$ for people with diabetes; the between-run CV was $1.61 \%$ and $1.16 \%$ respectively. Blood samples were collected with a $\mathrm{HbA}_{1 \mathrm{c}}$ capillary collection system (Bio-Rad) and analysed within 2-6 days (according to the manufacturer's manual, which specified not before the end of $24 \mathrm{~h}$ after blood collection to enable complete Schiff-Base removal). Specimens prepared using this procedure are stable for 2 weeks at room temperature or for 4 weeks at $2-8^{\circ} \mathrm{C}$. Blood samples were not shipped. The Bio-Rad Variant device was located in the hospital building in a temperature-controlled laboratory room (ambient temperature maintained at $20-25^{\circ}$ throughout study period). All $\mathrm{HbA}_{1 \mathrm{c}}$ measurements were labelled by their original date. Laboratory personnel were not aware which results would be used in the study and were instructed not to perform any additional actions concerning $\mathrm{HbA}_{1 \mathrm{c}}$ measurements during the study period.

Meteorological data Meteorological data were provided by the Institute of Meteorology and Water Management station at Lodz-Lublinek Airport. Three weather-related variables were included in the analysis: (1) mean monthly ambient temperature in centigrade, measured using a meteorological station (MAWS301; Vaisala, Helsinki, Finland); (2) mean monthly duration of bright sunshine (hours of sunshine quantified as $\mathrm{h}$ per month); and (3) mean monthly solar irradiance (in $\mathrm{J} / \mathrm{cm}^{2}$ ). The two latter variables were measured using a pyranometer (CM5; Kip\&Zonen, Delft, the Netherlands). Both devices were compliant with the World Meteorological Organization and national standards.

Ethical approval This study protocol was approved by the Local Ethics Committee of the Medical University of Lodz (No RNN/98/10/KE). Guardians of all study participants gave informed consent.

Statistical analysis Fluctuations of mean $\mathrm{HbA}_{1 \mathrm{c}}$ levels were analysed throughout the study period, divided into months. Following outlier correction procedure (upper and lower 2.5 percentiles of $\mathrm{HbA}_{1 \mathrm{c}}$ ), mean $\mathrm{HbA}_{1 \mathrm{c}}$ values were used for seasonal variability evaluation through autocorrelations, a method that is aimed at internal pattern detection and based on mean correlation values between preceding and subsequent values of $\mathrm{HbA}_{1 \mathrm{c}}$ measured in months distant from each other by set intervals. A gap in data for July 2007 (due to the nationwide physicians' strike, during 
which no routine metabolic control visits were scheduled within the Clinic) was replaced by interpolated values of four adjacent values for the purpose of uninterrupted time-series analysis. Sun exposure data were also used for autocorrelation analysis. After comparison of autocorrelation patterns, patterns of metabolic control and meteorological data were evaluated using Spearman's rank correlation with appropriate corrections for multiple comparisons. Statistical significance was set at $p \leq 0.05$. Analyses were performed using Statistica 8.0 PL software (Statsoft, Tulsa, OK, USA).

\section{Results}

Of the 5,203 measurements performed in type 1 diabetes patients treated at the study centre, 3,935 were available for analysis from 677 children with type 1 diabetes after exclusion of measurements from patients with monogenic diabetes (MODY or permanent neonatal diabetes mellitus, $n=92$ ), patients older than 18 years or those with diabetes duration of less than 12 months $(n=950)$, measurements done in July 2007 (time of Health Professional Strike) $(n=$ 19) and outliers determined by values falling in the lowest and highest $2.5 \%(n=207)$. Of these 677 children, 88 were of preschool age ( $<7$ years old) and 589 were in primary and secondary school ( $\geq 7$ years old). Clinical characteristics of the total study group and of the two subgroups are presented in Table 1. The mean $( \pm \mathrm{SD}) \mathrm{HbA}_{1 \mathrm{c}}$ levels for the whole study period was $7.65 \pm 1.12 \%$. The highest $\mathrm{HbA}_{1 \mathrm{c}}$ levels were observed during February, November and December, while August and September showed the lowest $\mathrm{HbA}_{1 \mathrm{c}}$ levels. The differences between mean $\mathrm{HbA}_{1 \mathrm{c}}$ levels in late summer and winter months consistently exceeded $0.44 \%$. The maximum difference between means of $\mathrm{HbA}_{1 \mathrm{c}}$ in any two months of the study period was $0.72 \%$ (February 2008 vs September 2009). Variables of respective months including number of measurements, means and medians with 25 to $75 \%$ ranges are presented in the Electronic supplementary material (ESM), Table 1. A linear decreasing trend of $\mathrm{HbA}_{1 \mathrm{c}}$ values over time was present throughout the study period, but did not reach statistical significance
$(R=-0.26 ; p=0.11)$ and is shown in ESM Fig. 1. Increases and decreases of mean monthly $\mathrm{HbA}_{1 \mathrm{c}}$ were inversely related to average sun exposure across months as shown in Fig. 1. Periodicity of cycles equalled roughly 12 months, suggestive of a positive correlation between months 1 year apart and a negative correlation for intervals of 6-7 months, reflecting seasonal variability. Autocorrelations of $\mathrm{HbA}_{1 \mathrm{c}}$ declined in strength after two cycles below estimated white noise strength. Sun exposure and ambient temperature data showed a pattern with a periodicity of 11-13 months, with greater amplitude than $\mathrm{HbA}_{1 \mathrm{c}}$ autocorrelations (ESM Fig. 2a-d). Mean $\mathrm{HbA}_{1 \mathrm{c}}$ levels showed a sine-wave pattern of autocorrelations only in schoolchildren (superimposed autocorrelograms for $\mathrm{HbA}_{1 \mathrm{c}}$ with ambient temperature and hours of sunshine per month in schoolchildren are shown in Fig. 2a). Such associations were not observed in preschool children, in whom $\mathrm{HbA}_{1 \mathrm{c}}$ levels showed only white noise variability without any evidence of association with ambient temperature or sun exposure (Fig. 2b). In schoolchildren, correlation analysis showed a statistically significant negative correlation between $\mathrm{HbA}_{1 \mathrm{c}}$ and sun exposure data by hours of sunshine $(R=-0.52 ; p=0.0007)$, solar irradiance $(R=-0.52 ; p=0.0006)$ and ambient temperature $(R=-0.56 ; p=0.0002)$ as shown in Fig. 3a-c. Such associations were not significant in preschoolers, where neither hours of sunshine $(R=-0.10 ; p=0.52)$, solar irradiance $(R=$ $-0.06 ; p=0.69)$ or ambient temperature $(R=-0.18 ; p=0.29)$ correlated with $\mathrm{HbA}_{1 \mathrm{c}}$ levels (Fig. $3 \mathrm{~d}-\mathrm{f}$ ).

\section{Discussion}

This retrospective analysis of $\mathrm{HbA}_{1 \mathrm{c}}$ levels in 677 children and adolescents with type 1 diabetes over more than 3 years revealed a clear seasonal variability with 11-13 months periodicity. Similar results have been described in patients with diabetes by others [4-11]. In our study, the lowest $\mathrm{HbA}_{1 \mathrm{c}}$ levels were observed in August and September, while peaks were found in November, December and February. Poland, situated on the northern hemisphere, has a moderate climate, and these months correspond to late summer and late autumn/early winter respectively. Mean
Table 1 Characteristics of the study group

Unless otherwise specified, data are median (with $25-75 \%$ range) ${ }^{\text {a }} p<1 \times 10^{-4}$ in Mann-Whitney $U$ test

\begin{tabular}{llll}
\hline Variable & Total group & Preschool children & Schoolchildren \\
\hline Sex & & & \\
Female (n) & 290 & 35 & 255 \\
Male (n) & 387 & 53 & 334 \\
Age (years) & $13.3(9.1-15.9)$ & $6.0(4.9-6.5)$ & $14.0(11.1-16.3)$ \\
Diabetes duration (years) & $3.9(2.1-7.1)$ & $2.0(1.5-2.8)^{\mathrm{a}}$ & $4.3(2.4-7.6)^{\mathrm{a}}$ \\
$\mathrm{HbA}_{1 \mathrm{c}}(\%)$ & $7.39(6.83-8.10)$ & $7.10(6.72-7.60)^{\mathrm{a}}$ & $7.44(6.85-8.19)^{\mathrm{a}}$ \\
$\mathrm{HbA}_{1 \mathrm{c}}$ measurements (n) & $5(3-9)$ & $3(2-5)^{\mathrm{a}}$ & $6(3-9)^{\mathrm{a}}$ \\
\hline
\end{tabular}




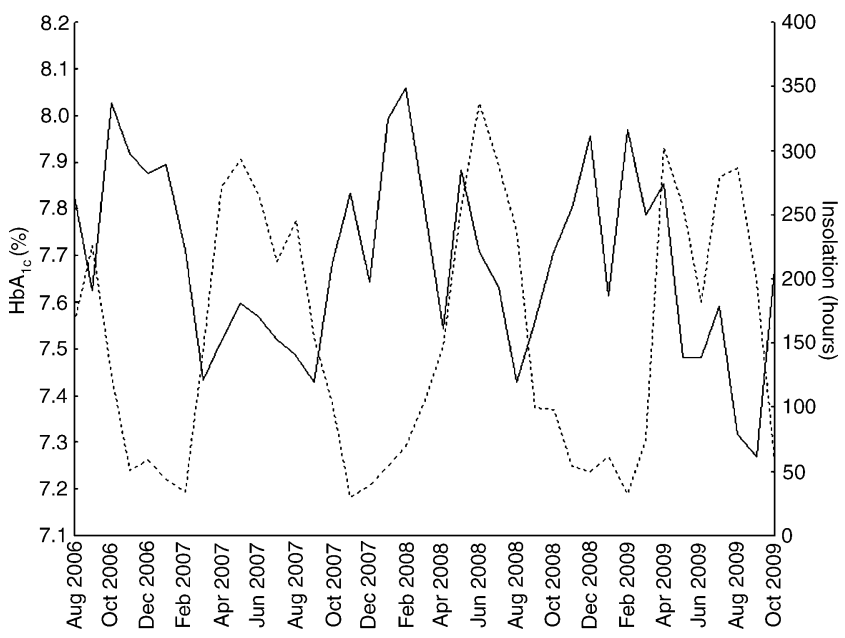

Fig. 1 Fluctuations of $\mathrm{HbA}_{1 \mathrm{c}}$ and sun exposure (expressed as $\mathrm{h}$ of sunshine per month) during the study period. Continuous line, $\mathrm{HbA}_{1 \mathrm{c}}$; dotted line, sun exposure

summer temperatures in Poland are between 16.5 and $20.0^{\circ} \mathrm{C}$, mean temperatures in winter are between -6.0 and $0^{\circ} \mathrm{C}$. In the present study, winter-summer differences in $\mathrm{HbA}_{1 \mathrm{c}}$ levels for the study interval were from $0.44 \%$ in 2007 to $0.67 \%$ in 2009 . These values are high, compared with the results obtained by Gerstl et al. in a large cohort of young patients with diabetes observed over several years (mean values for September 7.86\% vs January 8.08\%) [11], but comparable to the observation of Sakura et al. in adult patients with diabetes, where the differences reached $0.45 \%$ [7].

Seasonal variations of $\mathrm{HbA}_{1 \mathrm{c}}$ can be attributed to several factors, which may be classified into two groups: (1) sun exposure/temperature-dependent factors such as physical activity, vitamin D deficiency, serum melatonin concentration; and (2) sun exposure /temperature-independent factors such as school stress, amount of leisure time, mild upper respiratory and other 'seasonal' infections, seasonal dietary patterns related to the seasonal availability of 'healthy food' and endogenous seasonal hormonal variations (e.g. cortisol) [13]. Herbst et al., in their study including a cohort of 19,143 patients with type 1 diabetes (aged 3-20 years), showed that the frequency of regular physical activity is one of the most important factors influencing $\mathrm{HbA}_{1 \mathrm{c}}$ levels and that $\mathrm{HbA}_{1 \mathrm{c}}$ levels were lower in patients with greater regular weekly physical activity [14]. In countries with moderate climates, both younger (5-6 years old) and older children (10-12 years old) spend more time outdoors in warmer months than in cooler months [15]. Tucker et al. provided summaries of studies published up to 2009 , which present evidence that quantitative measures of weather conditions correlate with physical activity of the general population, and particularly that of children [16]. Physical activity of schoolchildren, especially from urban areas, depends on after-school access to school gymnasiums and athletic fields, and on participation in organised activities. Sport facilities, however, are not well maintained, are poorly supported and access to them often costs money. Therefore the main kind of physical activity, especially for boys, are self-organised outdoor activities such as football or basketball, which are highly restricted by daylight hours. In the region covered by this study, about $35 \%$ of the population lives in rural areas. In rural areas the traditional 'manual labour' has become more mechanised and gradually requires less and less physical effort. Furthermore, on many farms, children with a chronic disease are still stigmatised as weaker, and as a result are often less burdened by physical work. There is also the global problem of increasingly sedentary lifestyles of children, resulting from the ever greater amounts of time spent in front of the computer, video games and television. Thus patterns of physical activity of children and adolescents from rural and urban areas are gradually becoming similar. Based on all these data, daylight hours and ambient
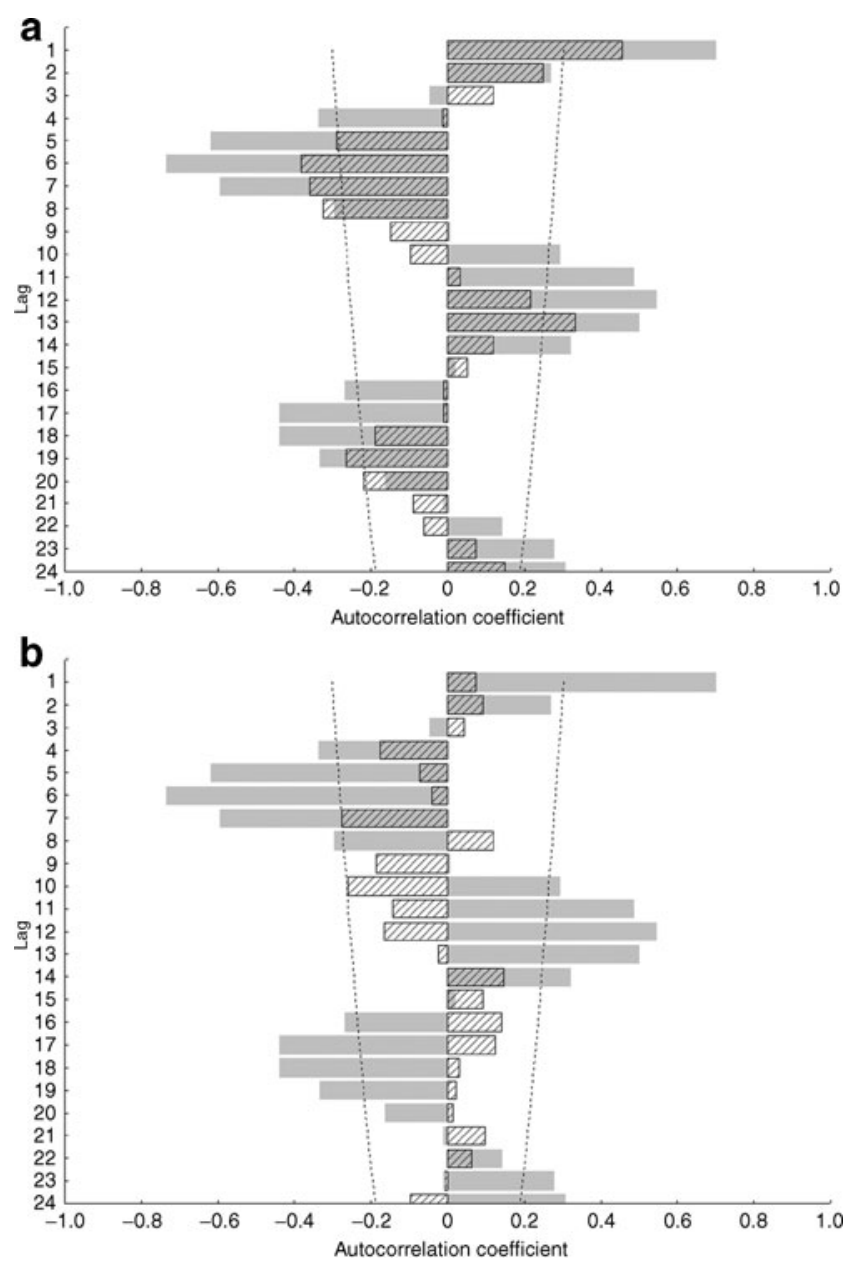

Fig. 2 Autocorrelation spectra of $\mathrm{HbA}_{1 \mathrm{c}}$ (hatched) and h of sunshine per month (grey) in (a) school and (b) preschool children. Dashed lines, $95 \%$ CIs of white noise expected for such a sample size 

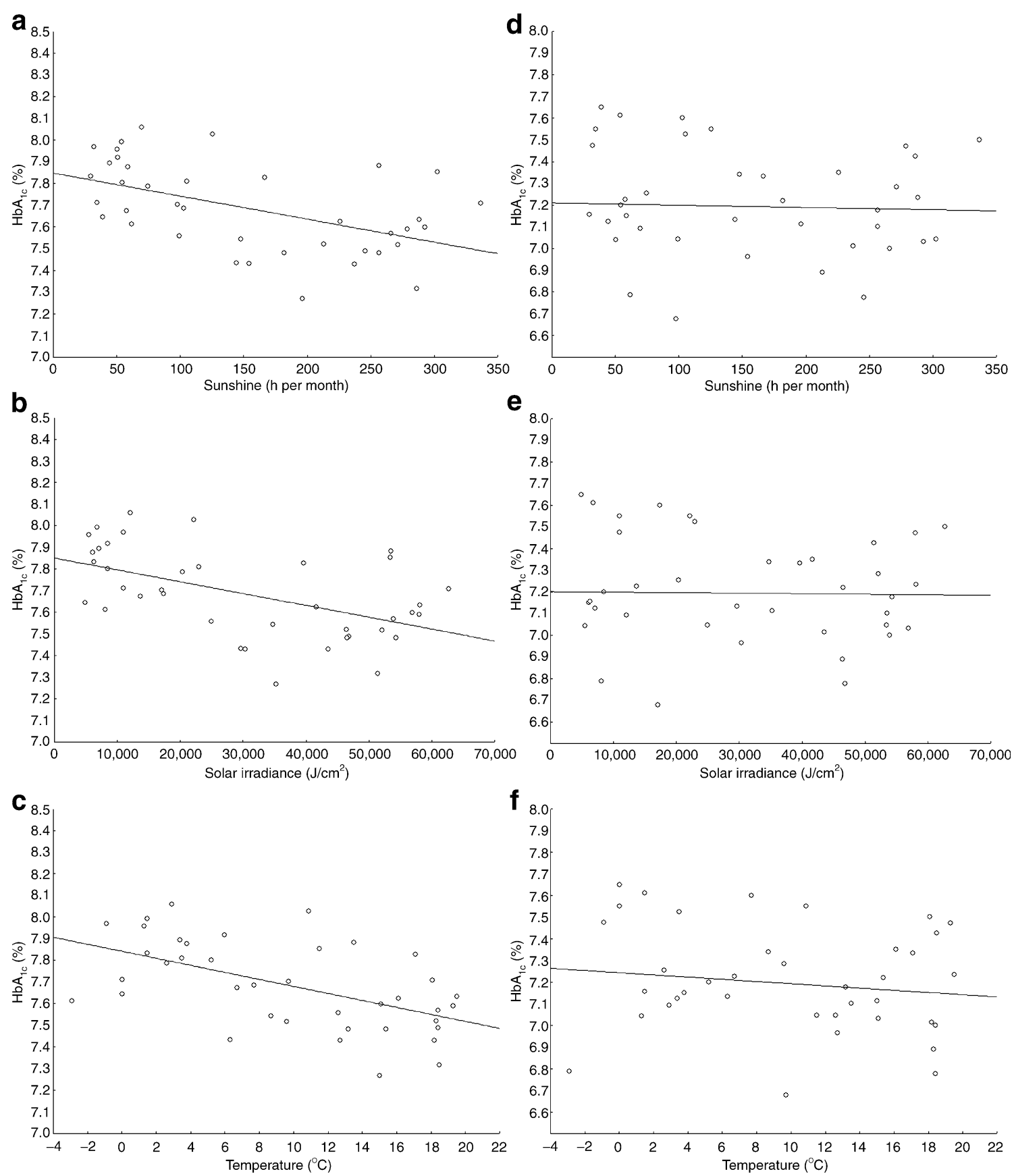

Fig. 3 Correlation of meteorological data, i.e. (a, d) h of sunshine per month, (b, e) solar irradiance and (c, f) ambient temperature, with $\mathrm{HbA}_{1 \mathrm{c}}$ levels in schoolchildren $(\mathbf{a}-\mathbf{c})$ and preschool children $(\mathbf{d}-\mathbf{f})$.

a $R=-0.52, p=0.0007$; (b) $R=-0.52, p=0.0006$; (c) $R=-0.56$, $p=0.0002$; (d) $R=-0.10, p=0.52$; (e) $R=-0.06, p=0.69$; (f) $R=-0.18, p=0.29$

temperature are good surrogates of physical activity in Poland, and so we examined their association with $\mathrm{HbA}_{1 \mathrm{c}}$ levels. Our study found a significant negative correlation between $\mathrm{HbA}_{1 \mathrm{c}}$ levels and 'good' weather conditions in schoolchildren, but not in preschoolers. Younger children, attending kindergarten or staying at home, are more physically active, both indoors and outdoors, than schoolchildren. During the school year, students spend many hours indoors, due to school work, which affects their daily physical activity

patterns. For schoolchildren, weather conditions, day length and the structure of the school year (especially summer holidays) strongly influence outdoor activities, while preschoolers, who are active all day and unrestricted by schoolassociated workload, seem to be less sensitive to these influences. An association between $\mathrm{HbA}_{1 \mathrm{c}}$ levels and quantified weather conditions, including sun exposure, has not been previously presented for children with diabetes. The data presented in this paper provide a physiological reason 
both for our findings of an annual pattern of $\mathrm{HbA}_{1 \mathrm{c}}$ levels and for similar results from other groups.

The trend in $\mathrm{HbA}_{1 \mathrm{c}}$ variation is consistent with seasonal variation of type 1 diabetes incidence [17, 18]. An inverse correlation with ultraviolet irradiance and diagnosis of type 1 diabetes has been observed in Newfoundland, Canada [19]. Both phenomena could be dependent on vitamin D synthesis in human skin [20]. The mechanism by which vitamin D possibly protects against type 1 diabetes is still unclear. Although there is some evidence suggesting that vitamin D may protect from cytokine-induced beta cell damage [21], such a mechanism provides little explanation of its association with metabolic control in stable, longstanding type 1 diabetes in children.

On the other hand, melatonin, which is secreted by the pineal gland, synchronises biological rhythms and follows a circadian and circannual rhythm. Melatonin is secreted in darkness and its level increases during the night [22] and in winter (December in the northern hemisphere) compared with daytime hours and summer (July) respectively [23]. Melatonin decreases insulin sensitivity, can decrease insulin secretion and can increase blood glucose levels, while phototherapy sessions (which potentially decrease melatonin levels) have been shown to induce recurrent hypoglycaemia in a patient with type 1 diabetes [24-26]. From these observations, one could conclude that higher melatonin levels persisting for a longer time during autumn and winter nights could contribute to higher blood glucose levels. Such an association seems to be even clearer than any relation between vitamin D deficiency and higher blood glucose levels observed in colder months in patients with overt type 1 diabetes.

Other seasonal factors such as different dietary habits (e.g. lower consumption of vegetables and greater fat intake in winter), seasonal changes in body fat content (higher in winter and decreased in summer), more frequent infections and higher cortisol or glucagon levels in autumn and winter than in summer, as well as school stress can also unfavourably influence $\mathrm{HbA}_{1 \mathrm{c}}$ levels through their effect on insulin sensitivity and blood glucose levels [5, 10, 11, 13, 27]. In Poland dietary habits may play an important role. Although food supply is generally unrestricted in the major food markets, due to the regional vegetation pattern prices of fresh vegetables and fruit increase during winter and early spring. In many households, especially those of poorer economic status, this may be compensated by higher intake of food rich in carbohydrates and fat. This can contribute to less favourable glycaemic profiles in young patients with type 1 diabetes who do not adapt their insulin doses appropriately.

Factors that can interfere with the performance of $\mathrm{HbA}_{1 \mathrm{c}}$ assays are: haemoglobin variants and derivatives, shortened erythrocyte survival, vitamin $\mathrm{C}$ and $\mathrm{E}$, iron deficiency anaemia, hypertriacylglycerolaemia, hyperbilirubinaemia, uraemia, chronic alcoholism, chronic ingestion of salicy- lates and opiate addiction (www.ngsp.org/factors.asp; accessed 25 November 2010). Two of these could be speculated to promote a seasonal pattern in a paediatric population, namely vitamin $\mathrm{C}$ (as potentially related to seasonal changes in vegetable and fruit intake) and hypertriacylglycerolaemia (related to increased fat intake). However, according to the Bio-Rad Variant Hemoglobin $A_{1 c}$ manual (for hypertriacylglycerolaemia) and data from the literature (for pharmacological doses of vitamin $\mathrm{C}$ ), none of these substances has any impact on HPLC-measured $\mathrm{HbA}_{1 \mathrm{c}}$ levels [28]. In respect to meteorological factors, neither the NGSP (www.ngsp.org/factors.asp; accessed 25 November 2010) nor the manufacturer's instruction manual mention ambient temperature, humidity or pressure as 'factors that interfere with $\mathrm{HbA}_{1 \mathrm{c}}$ results'.

Irrespective of their origin, the documented seasonal variations of $\mathrm{HbA}_{1 \mathrm{c}}$ levels should be considered in disease management schedules: adaptation of insulin doses, meal plans, advising and organising physical activity, prevention of physical activity-related fear of hypoglycaemia in young patients with type 1 diabetes and the use of $\mathrm{HbA}_{1 \mathrm{c}}$ as a tool for diabetes diagnosis. This may also be an important consideration for short-time (i.e. running over several months) clinical trials measuring before and after intervention $\mathrm{HbA}_{1 \mathrm{c}}$ levels. In patients using continuous subcutaneous insulin infusion (in many paediatric centres, including ours, more than $50 \%$ of patients use this), the basal rate is assessed and adjusted if needed at least every 3 months and could anticipate the observed seasonality of glycaemic control.

There are some limitations that may bias the results of the study. According to ADA recommendations, the $\mathrm{HbA}_{1 \mathrm{c}}$ test should be performed at least twice a year in patients with diabetes who are meeting glycaemic goals and at least four times a year in those who are not meeting treatment goals or whose therapy has changed [3]. The mean number of measurements among our study participants was 1.8 per patient per year, as some patients dropped out upon reaching the age of 18 years and some were evaluated only as inpatients during scheduled metabolic control assessment. However, a small number of measurements per patient reduces the effect of within-patient variability, as patients with better control have fewer observations with less variability and those with higher $\mathrm{HbA}_{1 \mathrm{c}}$ and more frequent testing may weigh the analysis, causing false peaks of bad metabolic control. We would expect this effect to be randomly distributed across the year, thus not biasing any seasonal trend. Another limitation of our analysis is that $\mathrm{HbA}_{1 \mathrm{c}}$ measurements may be affected by factors independent of seasonal variations. $\mathrm{HbA}_{1 \mathrm{c}}$ measurements incorporate the potential biases of a different number of measurements per patient, this is in contrast to the measures of weather variation, which can be observed under consistent conditions. Thus, mean $\mathrm{HbA}_{1 \mathrm{c}}$ levels may depend on the 
number of measurements each month and sampling of particular patients, while average sun exposure and temperature do not have such variation and allows for a continuous time series composed of the same number of measurements each month. A slight time delay in autocorrelations of $\mathrm{HbA}_{1 \mathrm{c}}$ and weather conditions was also noted. It was probably due to the fact that the $\mathrm{HbA}_{1 \mathrm{c}}$ level is an intrinsically time-lagged variable and depends strongly on the previous 3 months of glycaemic control. Autocorrelations of $\mathrm{HbA}_{1 \mathrm{c}}$ were observed to dwindle faster, due to initial lower strength, which is typical for such autocorrelation effects. Although this may affect the direct relationship of seasonal changes and $\mathrm{HbA}_{1 \mathrm{c}}$, the established pattern is still valid.

The strength of this study is that it covered a well documented, ethnically homogeneous (white) population with several long-running epidemiological projects such as the developing Nationwide Registry of Pediatric and Adolescent Diabetes and the Polish Registry of Neonatal Diabetes [29, 30]. From a geographic perspective, the region is characterised by the lack of mountains or seaside providing a stable temperate climate with daylight hours of sunshine varying continuously throughout the year and typically no natural disasters.

In conclusion, periodic changes of $\mathrm{HbA}_{1 \mathrm{c}}$ are a biologically significant phenomenon in young patients with type 1 diabetes and should be considered in patient education and diabetes management schedules. They may affect the results of paired, time-dependent comparisons in clinical trials using $\mathrm{HbA}_{1 \mathrm{c}}$ levels as their primary outcome and the $\mathrm{HbA}_{1 \mathrm{c}}$-based diagnosis of diabetes.

Acknowledgements The study was funded by TEAM programme 'Polish Registry for Pediatric and Adolescent Diabetes - nationwide genetic screening for monogenic diabetes' of the Innovative Economy Operational Program and Foundation for Polish Science. W. Fendler was supported by a research grant of the Polish Ministry of Science and Higher Education (N407 022135) and the Foundation for Development of Polish Pharmacy and Medicine. W. Mlynarski was supported by a research grant of the Polish Ministry of Science and Higher Education (N407 099437).

Duality of interest The authors declare that there is no duality of interest associated with this manuscript.

Open Access This article is distributed under the terms of the Creative Commons Attribution Noncommercial License which permits any noncommercial use, distribution, and reproduction in any medium, provided the original author(s) and source are credited.

\section{References}

1. Nathan DM, Kuenen J, Borg R, Zheng H, Schoenfeld D, Heine RJ (2008) Translating the A1C assay into estimated average glucose values. Diabetes Care 31:1473-1478

2. The Diabetes Control and Complications Trial Research Group (1993) The effect of intensive treatment of diabetes on the development and progression of long-term complications in insulin-dependent diabetes mellitus. The Diabetes Control and Complications Trial Research Group N Engl J Med 329:977-986

3. ADA (2010) Executive summary: Standards of medical care in diabetes - 2010. Diabetes Care (Suppl 1) 33:S4-S10

4. Carney TA, Guy SP, Helliwell CD (2000) Seasonal variation in HbAlc in patients with type 2 diabetes mellitus. Diabet Med 17:554-555

5. Sohmiya M, Kanazawa I, Kato Y (2004) Seasonal changes in body composition and blood $\mathrm{HbA} 1 \mathrm{c}$ levels without weight change in male patients with type 2 diabetes treated with insulin. Diabetes Care 27:1238-1239

6. Tseng CL, Brimacombe M, Xie M et al (2005) Seasonal patterns in monthly hemoglobin Alc values. Am J Epidemiol 161:565-574

7. Sakura H, Tanaka Y, Iwamoto Y (2010) Seasonal fluctuations of glycated hemoglobin levels in Japanese diabetic patients. Diabetes Res Clin Pract 88:65-70

8. Nordfeldt S, Ludvigsson J (2000) Seasonal variation of HbA1c in intensive treatment of children with type 1 diabetes. J Pediatr Endocrinol Metab 13:529-535

9. Scottish Study Group for the Care of the Young Diabetic (2001) Factors influencing glycemic control in young people with type 1 diabetes in Scotland: a population-based study (DIABAUD2). Diabetes Care 24:239-244

10. Hinde FRJ, Standen PJ, Mann NP, Johnston DI (1989) Seasonal variation of hemoglobin A1 in children with insulin-dependent diabetes mellitus. Eur J Pediatr 148:597-599

11. Gerstl EM, Rabl W, Rosenbauer J et al (2008) Metabolic control as reflected by $\mathrm{HbA} 1 \mathrm{c}$ in children, adolescents and young adults with type-1 diabetes mellitus: combined longitudinal analysis including 27, 035 patients from 207 centers in Germany and Austria during the last decade. Eur J Pediatr 167:447-453

12. Higgins T, Saw S, Sikaris K et al (2009) Seasonal variation in hemoglobin A1c: is it the same in both hemispheres? J Diabetes Sci Technol 3:668-671

13. Walker BR, Best R, Noon JP, Watt GC, Webb DJ (1997) Seasonal variation in glucocorticoid activity in healthy men. J Clin Endocrinol Metab 82:4015-4019

14. Herbst A, Bachran R, Kapellen T, Holl R, for the DPV Science Initiative (2006) Effects of regular physical activity on control of glycemia in pediatric patients with type 1 diabetes mellitus. Arch Pediatr Adolesc Med 160:573-577

15. Cleland V, Crawford D, Baur LA, Hume C, Timperio A, Salmon J (2008) A prospective examination of children's time spent outdoors, objectively measured physical activity and overweight. Int J Obes (Lond) 32:1685-1693

16. Tucker P, Gilliland J (2007) The effect of season and weather on physical activity: a systematic review. Public Health 121:909-922

17. Moltchanova EV, Schreier N, Lammi N, Karvonen M (2009) Seasonal variation of diagnosis of type 1 diabetes mellitus in children worldwide. Diabet Med 26:673-678

18. Ursic-Bratina N, Battelino $\mathrm{T}$, Krzisnik $\mathrm{C}$, Laron-Kenet $\mathrm{T}$, Ashkenazi I, Laron Z (2001) Seasonality of birth in children (014 years) with diabetes mellitus in Slovenia. J Pediatr Endocrinol Metab 14:47-52

19. Sloka S, Grant M, Newhook LA (2008) Time series analysis of ultraviolet B radiation and type 1 diabetes in Newfoundland. Pediatr Diabetes 9:81-86

20. Zipitis CS, Akobeng AK (2008) Vitamin D supplementation in early childhood and risk of type 1 diabetes: a systematic review and meta-analysis. Arch Dis Child 93:512-517

21. Mathieu C, Gysemans C, Giulietti A, Bouillon R (2005) Vitamin D and diabetes. Diabetologia 48:1247-1257

22. Lynch HJ, Wurtman RJ, Moskowitz MA, Archer MC, Ho MH (1975) Daily rhythm in human urinary melatonin. Science 187:169-171 
23. Morera AL, Abreu P (2007) Daytime/night-time and summer/ winter melatonin and malondialdehyde rhythms: an inverse relationship. J Pineal Res 43:313-314

24. Cagnacci A, Arangino S, Renzi A et al (2001) Influence of melatonin administration on glucose tolerance and insulin sensitivity of postmenopausal women. Clin Endocrinol (Oxf) 54:339-346

25. Stamenkovic JA, Nagorny CLF, Ling C et al (2010) Melatonin effect on insulin secretion and clock genes expression. Diabetologia 53(Suppl 1):S46, Abstract

26. Nieuwenhuis RF, Spooren PFMJ, Tilanus JJD (2009) Less need for insulin, a surprising effect of phototherapy in insulin-dependent diabetes mellitus. Tijdschrifit voor Psychiatrie 51:693-697, article in Dutch
27. Kuroshima A, Doi K, Ohno T (1979) Seasonal variation of plasma glucagon concentration in men. Jpn J Physiol 29:661-668

28. Camargo JL, Stiff J, Gross JL (2006) The effect of aspirin and vitamin $\mathrm{C}$ and $\mathrm{E}$ on $\mathrm{HbA}_{1 \mathrm{c}}$ assays. Clin Chim Acta 372:206209

29. Borowiec M, Fendler W, Antosik K et al (2010) Optimization of monogenic diabetes screening programme-initial report on recruitment efficacy of the TEAM project. Pediatr Endocrinol Diabetes Metab 16:73-76

30. Gach A, Wyka K, Malecki MT et al (2007) Islet-specific antibody seroconversion in patients with long duration of permanent neonatal diabetes caused by mutations in the KCNJ11 gene. Diabetes Care 30:2080-2082 